\title{
Role of Structural Defects and Oxygen lon Migration in the Catalytic Activity of $\mathrm{La}_{2} \mathrm{O}_{3}$
}

\author{
Douglas J. llett and M. Saiful Islam* \\ Department of Chemistry, University of Surrey, Guildford, UK GU2 5XH
}

\begin{abstract}
Atomistic computer simulation techniques are used to investigate the role of key defect and transport properties of $\mathrm{La}_{2} \mathrm{O}_{3}$ that may be involved in the catalytic activity. The theoretical techniques are based upon efficient energy minimization procedures and Mott-Littleton methodology for accurate defect modelling. The interatomic potentials for $\mathrm{La}_{2} \mathrm{O}_{3}$ correctly reproduce the hexagonal structure. Anion Frenkel disorder is found to be the predominant intrinsic defect with negligible deviation from ideal stoichiometry, in accord with the known properties of the pure material. The highest solubility, for a range of dopants, is calculated for $\mathrm{Sr}$ which would increase the oxygen vacancy concentration; this is consistent with experimental studies of the promoted catalyst. A low activation for $\mathrm{O}^{2-}$ vacancy migration suggests fast diffusion through the bulk and to the surface. We suggest that the catalytic activity is linked to an oxidation reaction in which oxygen-hole centres are created from the annihilation of oxygen vacancies by reactant gas-phase oxygen. Furthermore, calculated binding energies indicate the possible formation of stable (dopant- $0^{-}$) centres.
\end{abstract}

Rare-earth-metal sesquioxides rank among the most active and selective catalysts for the oxidative coupling of methane to form higher hydrocarbon products (mainly ethane and ethene), ${ }^{1-14}$ a process of considerable importance in utilizing the large reserves of natural gas. In particular, $\mathrm{La}_{2} \mathrm{O}_{3}$ doped with $\mathrm{Sr}$ exhibits the highest activity and has the added advantage of good stability at reaction conditions.

The issue of the reaction mechanism is still unclear, but is thought to involve hydrogen-atom abstraction from methane by $\mathrm{O}^{-}$hole centres to generate methyl radicals followed by gas-phase recombination. The participation of other oxygen centres such as the $\mathrm{O}_{2}^{2-}$ peroxide species in the direct formation of ethene has also been proposed. ${ }^{5,12,14}$ More recently, a few studies ${ }^{9,13}$ have emphasized the relationship between the catalytic activity and the defect structure of pure and doped $\mathrm{La}_{2} \mathrm{O}_{3}$. For example, isotope exchange experiments ${ }^{13}$ provide evidence that facile oxygen ion diffusion within the bulk and to the surface plays a major role in the oxidative coupling reaction, and that $\mathrm{Sr}$ doping increases such oxygen mobility by increasing the number of $\mathrm{O}^{2-}$ vacancies.

The numerous investigations on the rare-earth-metal oxide catalysts have largely focused on testing studies of selectivity/ activity behaviour to identify the most effective catalysts. It is clear, however, that solid-state properties such as the precise role of structural defects and dopants, the energetics of oxygen ion diffusion, as well as the nature of redox reactions leading to the formation of electron hole $\left(\mathrm{O}^{-}\right)$centres are not well established and are crucial to the proper understanding of the catalytic properties of the $\mathrm{La}_{2} \mathrm{O}_{3}$ system.

In an attempt to clarify these issues we apply computer simulation techniques which are well suited to exploring solid-state properties at the atomic level. The reliability of such theoretical methods has been demonstrated by studies of a diverse range of polar solids including alkaline-earthmetal oxides, ${ }^{15}$ zeolites ${ }^{16}$ and oxide superconductors. ${ }^{17}$ The present simulations of the $\mathrm{La}_{2} \mathrm{O}_{3}$ bulk are a useful preliminary to more complex simulations of the surface which are currently being undertaken.

\section{Simulation Methods}

The simulations are formulated within the framework of the Born model, the main features of which are the nature of the interatomic potentials and the modelling of perfect and defective lattices. The present account of these widely used tech- niques (embodied in the CASCADE code ${ }^{18}$ ) will be brief since comprehensive reviews are given elsewhere. ${ }^{19}$

The effective potentials describing the interatomic forces are represented by ionic, pair-wise potentials of the form

$$
U=\sum_{i j} \frac{q_{i} q_{j}}{r_{i j}}+\sum_{i j} \phi_{i j}\left(r_{i j}\right)
$$

which includes a long-range Coulombic interaction, and a short-range term to model the repulsions and van der Waals attractions between electron charge clouds. The latter shortrange term is typically described by an analytical function of the Buckingham form:

$$
\phi_{i j}\left(r_{i j}\right)=A_{i j} \exp \left(-r_{i j} / \rho_{i j}\right)-C_{i j} / r_{i j}
$$

Ionic polarisation is treated by the shell model ${ }^{20}$ which represents each ion in terms of a massless shell (simulating the valence shell electrons) and a core, coupled by a harmonic spring. The development of a dipole moment is effected by the displacement of the shell relative to the core.

The static simulation of the perfect lattice gives the crystal structure and the lattice energy, which employs efficient energy minimization methods based on a Newton-Raphson (i.e. second derivative) procedure. Having attained the minimum energy structure, subsequent calculations of the second derivatives of the energy with respect to atomic coordinates yield information required to determine elastic and dielectric properties.

The defect energies are calculated within the context of the Mott-Littleton approach ${ }^{19,21}$ in which the ions in an inner region immediately around the defect are relaxed explicitly until they experience no net forces. In contrast, in the more distant regions of the crystal, the forces are relatively weak and are treated by methods based on continuum theories. There is now ample evidence that given reliable interatomic potentials and a sufficiently large inner region these methods can produce accurate values for defect formation, migration and interaction energies.

\section{Potentials for $\mathrm{La}_{2} \mathrm{O}_{3}$}

$\mathrm{La}_{2} \mathrm{O}_{3}$ crystallizes into a hexagonal structure (space group $P \overline{3} m 1)^{22}$ with an unusual seven-coordination of the cation (Fig. 1). The unit cell consists of one independent $\mathrm{La}$ ion and two independent $\mathrm{O}$ atoms. The $\mathrm{La}$ and $\mathrm{O}(1)$ form double hexagonal layers of alternating $\mathrm{La}$ and $\mathrm{O}$ and these layers are 


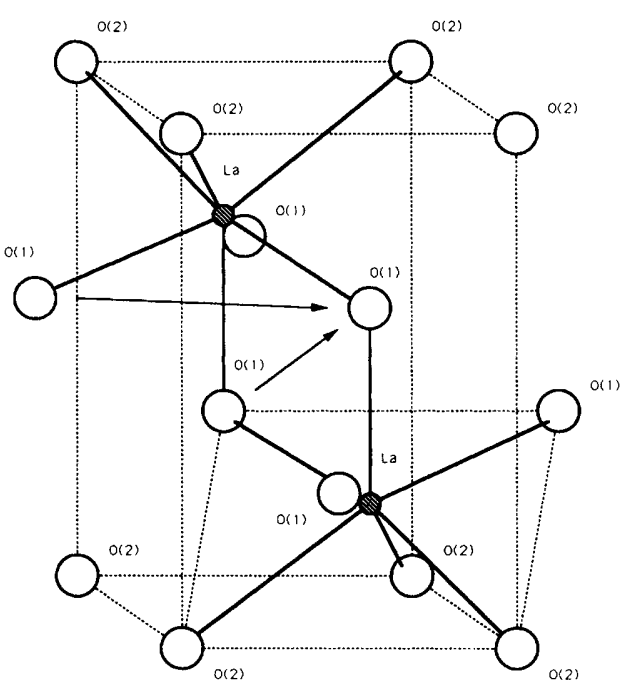

Fig. 1 Hexagonal structure of $\mathrm{La}_{2} \mathrm{O}_{3}$ (after ref. 22). Arrows indicate possible pathways for oxygen vacancy migration.

held together by $\mathrm{O}(2)$. The potential parameters for $\mathrm{La}_{2} \mathrm{O}_{3}$ are derived from electron-gas methods and were recently applied to pressure simulations ${ }^{23}$ of $\mathrm{La}_{2} \mathrm{CuO}_{4}$. Integral ionic charges are presumed, i.e. $3+$ for $\mathrm{La}$ and $2-$ for $\mathrm{O}$, which enables a simple definition of hole states (as $\mathrm{O}^{-}$) and the useful concept of isovalent or aliovalent dopant substitution. Details of the potential and shell model parameters used in this study are given in Table 1 .

A comparison between calculated and experimental interatomic separations, presented in Table 2, indicates that the deviation is generally small. This clearly shows that the potentials for $\mathrm{La}_{2} \mathrm{O}_{3}$ correctly reproduce the complex hexagonal structure, without employing empirical fitting pro-

Table 1 Interatomic potentials for $\mathrm{La}_{2} \mathrm{O}_{3}$

(a) Short-range: $V(r)=\mathrm{A} \exp (-r / \rho)-C / r^{6}$

\begin{tabular}{lrcc}
\hline interaction & \multicolumn{1}{c}{$A / \mathrm{eV}$} & $\rho / \AA$ & $C / \mathrm{eV} \AA^{-6}$ \\
\hline $\mathrm{La}^{3+} \ldots \mathrm{La}^{3+}$ & 85791.74 & 0.22030 & 6.8630 \\
$\mathrm{La}^{3+} \ldots \mathrm{O}^{2-}$ & 5700.52 & 0.29885 & 38.9365 \\
$\mathrm{O}^{2-} \ldots \mathrm{O}^{2-}$ & 576.94 & 0.33536 & 0.0 \\
$\mathrm{La}^{3+} \ldots \mathrm{O}^{-}$ & 5700.52 & 0.29885 & 38.9365 \\
$\mathrm{O}^{2-} \ldots \mathrm{O}^{-}$ & 576.94 & 0.33536 & 0.0 \\
\hline
\end{tabular}

(b) Shell model ${ }^{a}$

\begin{tabular}{lcc}
\hline species & $Y / \mathrm{e}$ & $k / \mathrm{eV} \AA^{-2}$ \\
\hline $\mathrm{La}^{3+}$ & -6.00 & 460.0 \\
$\mathrm{O}^{2-}$ & -2.50 & 27.0 \\
$\mathrm{O}^{-}$ & -1.50 & 27.0 \\
\hline
\end{tabular}

${ }^{a} Y$ and $k$ are the shell charge and spring constant, respectively.

Table 2 Calculated and observed interatomic separations $/ \AA$

\begin{tabular}{lccc}
\hline separation & $r$ (expt) & $r$ (calc) & $|\Delta|$ \\
\hline La-O(1) & 2.371 & 2.378 & 0.007 \\
La-O(1) & 2.451 & 2.335 & 0.116 \\
La-O(2) & 2.720 & 2.724 & 0.004 \\
O(1)-O(1) & 2.886 & 2.791 & 0.094 \\
O(1)-O(2) & 3.147 & 3.173 & 0.026 \\
La-La & 3.865 & 3.799 & 0.066 \\
\hline
\end{tabular}

Table 3 Calculated properties of the perfect crystal

\begin{tabular}{lc}
\hline \multicolumn{1}{c}{ property } & $\mathrm{La}_{2} \mathrm{O}_{3}$ \\
\hline lattice energy/eV formula unit ${ }^{-1}$ & -130.53 \\
$\mathrm{a}(\AA)$ & $3.887(3.938)^{a}$ \\
$\mathrm{c}(\AA)$ & $6.059(6.128)^{a}$ \\
elastic constants $/ 10^{11} \mathrm{dyn} \mathrm{cm}^{-2}$ & \\
$c_{11}$ & 32.02 \\
$c_{12}$ & 15.20 \\
$c_{13}$ & 12.06 \\
$c_{33}$ & 22.38 \\
$c_{44}$ & 11.45 \\
$c_{66}$ & 8.41 \\
relative permittivities & \\
$\left\langle\varepsilon_{0}\right\rangle$ & 18.3 \\
$\left\langle\varepsilon_{\infty}\right\rangle$ & 3.9 \\
\hline
\end{tabular}

${ }^{a}$ Observed values ${ }^{22}$ in parentheses.

cedures. One of the largest errors is in the $\mathrm{O}(1)-\mathrm{O}(1)$ distance which may lead to some uncertainty in the calculated migration profiles. The lattice energy, elastic and dielectric constants for the perfect crystal have also been calculated and reported in Table 3. Unfortunately, corresponding experimental data for comparison are unavailable although our calculated static relative permittivity is consistent with experimental values ${ }^{24}$ of 15.7 and 16.2 for $\mathrm{Gd}_{2} \mathrm{O}_{3}$ and $\mathrm{Lu}_{2} \mathrm{O}_{3}$ respectively. To our knowledge these studies are the first detailed survey of the $\mathrm{La}_{2} \mathrm{O}_{3}$ catalyst employing simulation methods.

\section{Results and Discussion}

\section{Intrinsic Atomic Defects}

Calculations were first performed on the energies of isolated point defects (vacancies and interstitials) which are given in Table $4(a)$. In all cases, the lattice ions surrounding the defect are allowed to relax in the energy minimization procedure. For vacancies the energy corresponds to removing a lattice ion from the perfect crystal to infinity; likewise, the interstitial energy corresponds to introducing an ion from infinity into the perfect crystal.

The oxygen vacancy energies clearly indicate that it is more favourable to form vacancies in the four-coordinate $O(1)$ rather than octahedral $O(2)$ positions. For the interstitial ions, various sites in the structure were considered. The most favourable position is located between adjacent $\mathrm{La}$

Table 4 (a) Calculated energies of isolated point defects ${ }^{a}$

\begin{tabular}{cc}
\hline defect & $E / \mathrm{eV}$ \\
\hline $\mathrm{La}^{3+}$ vacancy $\left(\mathrm{V}_{\mathrm{La}}^{\prime \prime \prime}\right)$ & 48.64 \\
$\mathrm{O}^{2-}(1)$ vacancy $\left(\mathrm{V}_{0}^{*}\right)$ & 16.66 \\
$\mathrm{O}^{2-}(2)$ vacancy $\left(\mathrm{V}_{0}^{-}\right)$ & 17.71 \\
$\mathrm{La}^{3+}$ interstitial $\left(\mathrm{La}_{i}^{\circ}\right)^{b}$ & -34.16 \\
$\mathrm{O}^{2-}$ interstitial $\left(\mathrm{O}_{\mathrm{i}^{\prime}}^{\prime \prime}\right)^{b}$ & -11.51 \\
\hline
\end{tabular}

(b) Calculated formation energies of Frenkel and Schottky disorder

\begin{tabular}{cc}
\hline type & $E / \mathrm{eV}$ per defect \\
\hline Frenkel & \\
$\mathrm{La}^{3+}$ & 7.24 \\
$\mathrm{O}^{2-}$ & 2.57 \\
$\mathrm{Schottky}^{-}$ & 3.34 \\
\hline
\end{tabular}

${ }^{a}$ Region I contains 250 ions. ${ }^{b}$ Interstitial site at $(0.32,0.56,0.5)$ in lattice units. 
layers and at the centre of a 'cage' which has eight-fold coordination with respect to oxygen.

The individual point defect energies are then combined to give formation energies for Frenkel and Schottky disorder [reported in Table $4(b)$ ]. The La and O Frenkel defects can be represented by the following reactions using Kroger-Vink notation:

$$
\begin{aligned}
\mathrm{La}_{\mathrm{La}}^{x} & \rightarrow V_{\mathrm{La}}^{\prime \prime \prime}+\mathrm{La}_{\mathrm{i}} \\
\mathrm{O}_{0}^{x} & \rightarrow V_{0}^{\ddot{*}}+\mathrm{O}_{\mathrm{i}}^{\prime \prime}
\end{aligned}
$$

and similarly the Schottky defect can be expressed as:

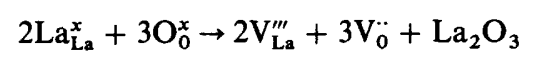

From examination of the calculated energies in Table $4(b)$ it is clear that the simulations predict that the predominant mode of intrinsic defect is of the oxygen Frenkel type. This result accords well with work of Anshits et al. ${ }^{9}$ and Kofstad ${ }^{25}$ who postulated that oxygen Frenkel defects would dominate in pure $\mathrm{La}_{2} \mathrm{O}_{3}$. Hence, ionic conduction will be undoubtedly controlled by the diffusion of oxygen defects, although the magnitude of the Frenkel energy suggests that the defect concentration will be very low in the pure material. It is interesting to note that the hexagonal A-type structure of $\mathrm{La}_{2} \mathrm{O}_{3}$ is closely related to the cubic C-type of other rare-earth-metal sesquioxides which, in turn, is derived from the fluorite structure. $^{22}$ Therefore, oxygen vacancies and interstitials might reasonably be expected in $\mathrm{La}_{2} \mathrm{O}_{3}$ since anion Frenkel disorder is commonly observed in fluorite-structured oxides. $^{25}$

\section{Electronic Defects}

Our approach to the investigation of electronic defects follows that used for transition metal oxides ${ }^{15}$ and subsequently the oxide superconductors. ${ }^{17,26}$ Calculations were performed on the $\mathrm{O}^{-}$substitutional which is the model for the hole centre in $\mathrm{La}_{2} \mathrm{O}_{3}$ and on the $\mathrm{La}^{2+}$ substitutional a model for the defect electron. Two types of calculation were carried out in each case: first a conventional calculation in which the lattice was fully relaxed around the defect species (referred to as a 'thermal' calculation); the resulting energy corresponds to the small polaron. In the second type only the shells were relaxed (referred to as an 'optical' calculation) which, as discussed previously, ${ }^{15}$ provides a model for the large polaron. Therefore, in the small polaron picture the electronic defect is localized and self-trapped by its own polarization field; in contrast, the large polaron is delocalized with no contribution from lattice distortion.

The lattice energy changes for the $\mathrm{O}^{-}$and $\mathrm{La}^{2+}$ species are reported in Table 5 together with various atomic and bandwidths terms. To estimate the small polaron energy the appropriate ionization energy or electron affinity is added to the lattice energy term. For the large polaron energy we also include half the bandwidth which approximates to the kinetic energy of the delocalized species. The resulting energies (given in Table 6) show first that the $\mathrm{O}^{-}$hole is a large polaron state on the $O(2)$ site; for electrons, on the other hand, we predict small polarons. By combining the two energies we obtain an estimate of $10 \mathrm{eV}$ for the band gap which accords with the $\mathrm{La}_{2} \mathrm{O}_{3}$ material being a wide-gap insulator. ${ }^{27}$ Of course, there are uncertainties in the relative energies which are due largely to uncertainties in the bandwidth contributions. Nevertheless, these results are consistent with the type of electronic species found in the $\mathrm{MgO}$ catalyst and the band gap characteristics of related sesquioxides. ${ }^{27}$

In addition to intrinsic disorder of the Frenkel and Schottky type there is also the question of whether there is
Table 5 (a) Calculated lattice energy changes/eV for electronic defects

\begin{tabular}{lcc}
\multicolumn{1}{c}{ defect } & small polaron $^{a}$ & large polaron $^{a}$ \\
\hline $\mathrm{O}^{-}(1)$ hole $\left(\mathrm{h}^{\circ}\right)$ & 15.30 & 18.36 \\
$\mathrm{O}^{-}(2)$ hole $\left(\mathrm{h}^{\circ}\right)$ & 14.12 & 15.98 \\
$\mathrm{La}^{2+}$ electron $\left(\mathrm{e}^{\prime}\right)$ & 24.71 & 25.86 \\
\hline
\end{tabular}

(b) Atomic and bandwidth energies ${ }^{b}$

\begin{tabular}{cc}
\hline term & energy/eV \\
\hline$E_{i, 3}{ }^{c}$ & 19.18 \\
$E_{\text {ea, } 1}{ }^{d}$ & -1.47 \\
$E_{\text {ea, }}{ }^{d}$ & 8.75 \\
$D_{e} e^{2}$ & 5.16 \\
O bandwidth & $c a .5$ \\
La bandwidth & $c a .2$ \\
\hline
\end{tabular}

"Small- and large-polaron energies refer to 'thermal' and 'optical' calculations respectively. ${ }^{b} \mathrm{O}$ bandwidths from ref. 26 and La bandwidth from ref. $27 .{ }^{c} E_{i, 3}$ is the third ionization potential of La. ${ }^{d} E_{\text {ea, } 1}$ and $E_{\text {ea, } 2}$ are the first and second electron affinities of oxygen. ${ }^{e} D_{c}$ is the dissociation energy of an $\mathrm{O}_{2}$ molecule.

any deviation from the stoichiometric composition. The following defect models might be expected under both oxidizing and reducing atmospheres leading to a degree of nonstoichiometry:

(i) oxidation to form holes $\left(\mathrm{O}^{-}\right)$with oxygen interstitial compensation (which produces an oxygen-excess compound):

$$
\frac{1}{2} \mathrm{O}_{2}(\mathrm{~g}) \rightarrow O_{\mathrm{i}}^{\prime \prime}+2 \mathrm{~h}^{\circ}
$$

(ii) oxidation to form holes $\left(\mathrm{O}^{-}\right)$with cation vacancy compensation (metal-deficient compound):

$$
\frac{1}{2} \mathrm{O}_{2}(\mathrm{~g})+\frac{2}{3} \mathrm{La}_{\mathrm{La}}^{x} \rightarrow \frac{2}{3} \mathrm{~V}_{\mathrm{La}}^{\prime \prime \prime}+2 \mathrm{~h}^{\bullet}+\frac{1}{3} \mathrm{La}_{2} \mathrm{O}_{3}
$$

(iii) reduction to form electron states $\left(\mathrm{La}_{\mathrm{La}}^{\prime}\right)$ with oxygen vacancy compensation (oxygen-deficient compound):

$$
\mathrm{O}_{0}^{x} \rightarrow \mathrm{V}_{0}^{\ddot{1}}+\frac{1}{2} \mathrm{O}_{2}(\mathrm{~g})+2 \mathrm{e}^{\prime}
$$

(iv) reduction to form electron states $\left(\mathrm{La}_{\mathrm{La}}^{\prime}\right)$ with cation interstitial compensation (metal-excess compound):

$$
\frac{1}{3} \mathrm{La}_{2} \mathrm{O}_{3} \rightarrow \frac{2}{3} \mathrm{La}_{\mathrm{i}} \cdots+\frac{1}{2} \mathrm{O}_{2}(\mathrm{~g})+2 \mathrm{e}^{\prime}
$$

The energies of these reactions are listed in Table 7 , and are derived using relevant defect energies (Table 4) and intraatomic energy terms (given in Table 5). Owing to the uncertainties in the free ion terms, we must be cautious in giving detailed interpretations. Nevertheless, the high positive values for all the oxidation and reduction reactions suggests that deviation from ideal stoichiometry is not significant in $\mathrm{La}_{2} \mathrm{O}_{3}$ in agreement with the known properties of the material. ${ }^{9,25}$ In particular, the oxide is extremely resistant to reduction. Our results therefore confirm that metal centres having variable oxidation states are not a prerequisite for methane oxidative coupling. ${ }^{5}$

Table 6 Formation energies for electronic defect/eV

\begin{tabular}{ccc}
\hline \multicolumn{1}{c}{ defect } & small polaron & large polaron \\
\hline $\mathrm{O}^{-}(1)$ hole $\left(\mathrm{h}^{\circ}\right)$ & 6.55 & 7.11 \\
$\mathrm{O}^{-}(2)$ hole $\left(\mathrm{h}^{\circ}\right)$ & 5.37 & 4.73 \\
$\mathrm{La}^{2+}$ electron $\left(\mathrm{e}^{\prime}\right)$ & 5.53 & 5.68 \\
\hline
\end{tabular}


Table 7 Calculated energies of redox reactions

\begin{tabular}{lc}
\hline redox process & $E / \mathrm{eV}$ \\
\hline oxidation & \\
reaction (IV) & 7.81 \\
reaction (V) & 8.24 \\
reduction & \\
reaction (VI) & 17.87 \\
reaction (VII) & 21.95 \\
\hline
\end{tabular}

\section{Oxygen Migration}

It is well established that solid-state diffusion, allowing the flow of oxygen from the gaseous phase (present as one of the reactants) into and through the bulk lattice, is of central importance to the mode of operation of certain oxidation catalysts. However, only a few studies ${ }^{13,28,29}$ have focused on oxygen diffusion in the $\mathrm{La}_{2} \mathrm{O}_{3}$ system. Early conductivity measurements of Etsell and Flengas ${ }^{28}$ obtained an activation energy of $17.1 \mathrm{kcal} \mathrm{mol}^{-1}(0.74 \mathrm{eV})$ for $\mathrm{CaO}$ doped $\mathrm{La}_{2} \mathrm{O}_{3}$, which they attribute to the motion of $\mathrm{O}^{2-}$ ions through either a vacancy or interstitial mechanism. Milne et al. ${ }^{29}$ have reported conductivity measurements as a function of $\mathrm{SrO}$ and $\mathrm{CaO}$ doping and obtained an activation energy of $0.6-0.7 \mathrm{eV}$ for the undoped limit. More recently, isotope exchange studies of Kalenik and Wolf ${ }^{13}$ have shown that lattice oxygen plays a major role during the oxidative coupling of methane; they also determined oxygen self-diffusion coefficients $\left(D_{0}\right)$ for the pure and promoted catalyst with the $1 \% \mathrm{Sr} / \mathrm{La}_{2} \mathrm{O}_{3}$ system exhibiting the highest value.

Despite the evident implications for the catalytic process, the precise nature of the migration mechanism or pathway controlling ion transport is still uncertain. Atomistic modelling can greatly enhance our understanding of this problem by evaluating the activation energies for various defect mechanisms.

For the hexagonal A-type structure of $\mathrm{La}_{2} \mathrm{O}_{3}$ there are a number of possible migration mechanisms. Since the formation energy of the $O(1)$ vacancy is significantly more favourable than the $O(2)$ position, we will focus our attention on the $O(1)$ sublattice for vacancy migration. Of the five mechanisms we have identified, two involve $\mathrm{O}^{2-}$ vacancies and the other three are concerned with $\mathrm{O}^{2-}$ interstitials. The two vacancy mechanisms are associated with intralayer and interlayer migration between neighbouring $O(1)$ sites; the three interstitial migration mechanisms relate to the direct pathway between the most favoured interstitial sites, and two interstitialcy or 'knock-on' mechanisms. The latter involves the migrating ion displacing a neighbouring lattice ion into the adjacent interstitial position. The importance of such interstitialcy mechanisms has been demonstrated by previous studies on fluorite-structured compounds.

The migration energies were evaluated by a detailed search of the potential-energy surface along the diffusion path. In this way the saddle-point configuration can be identified from which the energy barrier to migration is derived. It is clear from the numerous simulation studies of oxides that electrongas (non-empirical) potentials are particularly reliable in modelling the potential energy at separations widely different from perfect-lattice values. The resulting activation energies for oxygen vacancy and interstitial mechanisms are reported in Table 8.

Examination of the results indicates that interlayer vacancy migration clearly emerges as the lowest-energy path with an activation energy of $0.63 \mathrm{eV}$ (and at least $1.4 \mathrm{eV}$ more favourable than the other mechanisms considered). Interestingly, the corresponding interatomic separation of $2.89 \AA$ is the shortest $\mathrm{O}-\mathrm{O}$ distance in the structure. This result is consistent with
Table 8 Calculated activation energies for oxygen ion migration

\begin{tabular}{llc}
\hline mechanism & direction & $E_{\mathbf{2}} / \mathrm{eV}$ \\
\hline vacancy & & \\
$\mathrm{O}(1)-\mathrm{O}(1)$ & intralayer & 4.79 \\
$\mathrm{O}(1)-\mathrm{O}(1)$ & interlayer & 0.63 \\
interstitial & & \\
direct & & 2.10 \\
interstitialcy & collinear & 2.05 \\
interstitialcy & non-collinear & 3.08 \\
\hline
\end{tabular}

isotope exchange experiments ${ }^{13}$ which show fast oxygen diffusion. Moreover, the calculated activation energy is in good agreement with the observed values from ionic conductivity measurements. ${ }^{28,29}$ It is also clear that all the interstitial mechanisms have high energy barriers (Table 8), which implies that they would have a negligible contribution to oxygen transport.

To conclude, oxygen diffusion is predicted to be dominated by vacancies but restricted to interlayer migration between $\mathrm{O}(1)$ sites. In view of this type of motion, anisotropic ion conductivity is expected for single crystal $\mathrm{La}_{2} \mathrm{O}_{3}$. Furthermore, the low activation energy will permit facile oxygen vacancy migration (which effects transport of lattice $\mathrm{O}^{2-}$ ) through the bulk and to the catalyst surface. As is discussed further below, such high oxygen mobility will certainly have a major practical influence on methane activation.

\section{Dopant Substitution}

Numerous experimental studies have shown that the addition of alkali-metal and alkaline-earth-metal dopants (especially $\mathrm{Sr}^{2+}$ ) to $\mathrm{La}_{2} \mathrm{O}_{3}$ is effective in promoting oxidative coupling of methane. A wide range of catalytic activities and selectivities are exhibited which have yet to be optimized.

Our simulation approach is based on assessing the energetics of dissolution of such aliovalent ions and the nature of the charge-compensating defects in which we neglect defect entropy terms. The most straightforward mode of dopant incorporation into the host matrix is as a substitutional ion at a $\mathrm{La}^{3+}$ site with compensating oxygen vacancies. This can be represented by the following defect equations:

alkali metal: $\frac{1}{2} \mathrm{M}_{2} \mathrm{O}+\mathrm{La}_{\mathbf{L a}}^{x} \rightarrow \mathrm{M}_{\mathbf{L a}}^{\prime \prime}+\mathrm{V}_{0}^{\ddot{*}}+\frac{1}{2} \mathrm{La}_{2} \mathrm{O}_{3}$

alkaline-earth metal:

$$
\mathrm{MO}+\mathrm{La}_{\mathrm{La}}^{x} \rightarrow \mathrm{M}_{\mathrm{La}}^{\prime}+\frac{1}{2} \mathrm{~V}_{0}^{\ddot{*}}+\frac{1}{2} \mathrm{La}_{2} \mathrm{O}_{3}
$$

The energies of solution are then evaluated by combining appropriate defect and cohesive energy terms. For example, the energy of reaction (IX) can be expressed as:

$$
E_{\text {sol }}=E_{\text {sub }}+\frac{1}{2} E_{\mathrm{v}}+\frac{1}{2} U_{\mathrm{L}}\left(\mathrm{La}_{2} \mathrm{O}_{3}\right)-U_{\mathrm{L}}(\mathrm{MO})
$$

where $E_{\text {sub }}$ is the dopant substitutional energy, $E_{\mathrm{v}}$ is the oxygen vacancy energy and $U_{\mathrm{L}}$ is the lattice energy. We note that the entropy change and hence the temperature dependence can be obtained computationally and is currently being investigated.

The interatomic potentials for the dopant species are exactly those of corresponding binary metal oxides ${ }^{30}$ which have been successfully applied to recent studies ${ }^{17}$ of impurities in $\mathrm{La}_{2} \mathrm{CuO}_{4}$ and $\mathrm{YBa}_{2} \mathrm{Cu}_{3} \mathrm{O}_{7}$. The resulting energies of solution for a series of alkali-metal and alkaline-earth-metal ions are presented in Table 9 and are also plotted vs. ion radius in Fig. 2.

Two points emerge from these results. First, the lower solution energies for alkaline-earth-metal ions suggests a higher 
Table 9 Energies of solution for alkali-metal and alkaline-earthmetal dopants with oxygen vacancy compensation (reactions VIII and IX)

\begin{tabular}{lcc}
\hline \multicolumn{1}{c}{$\mathbf{M}$} & $U_{1} / \mathrm{eV}^{a}$ & $E_{\text {sol }} / \mathrm{eV}$ per dopant \\
\hline $\mathrm{Li}^{+}$ & -29.98 & 4.78 \\
$\mathrm{Na}^{+}$ & -24.75 & 3.82 \\
$\mathbf{K}^{+}$ & -22.18 & 4.47 \\
$\mathrm{Rb}^{+}$ & -21.18 & 5.09 \\
$\mathrm{Mg}^{2+}$ & -41.29 & 3.94 \\
$\mathrm{Ca}^{2+}$ & -36.10 & 2.30 \\
$\mathrm{Sr}^{2+}$ & -33.42 & 1.71 \\
$\mathrm{Ba}^{2+}$ & -33.74 & 4.93 \\
\hline
\end{tabular}

${ }^{a}$ Lattice energies from ref. 30.

solubility range than the alkali metals. The calculations therefore predict that alkaline-earth-metal doped $\mathrm{La}_{2} \mathrm{O}_{3}$ would show the greater activity which is consistent with observation. We recognize, however, the difficulty in assessing the relative activity/selectivity properties of the promoted catalyst since a diverse range of reaction conditions have been employed. The lower solubility of $\mathrm{Li}^{+}$and $\mathrm{Na}^{+}$may be explained in terms of the ion size 'mismatch' with $\mathrm{La}^{3+}$ (shown in Fig. 2) and, hence, they cannot be so readily accommodated in the lattice. In view of these high solution energies it is possible that the catalytic properties are associated with exsolved $\mathrm{Li}_{2} \mathrm{O}$ and $\mathrm{Na}_{2} \mathrm{O}$, but modified by interaction with the $\mathrm{La}_{2} \mathrm{O}_{3}$ host. Indeed, it is believed that the role of $\mathrm{Li}$ and $\mathrm{Na}$ is to poison the catalyst surface for total oxidation reactions. ${ }^{31}$ Secondly, the most favourable solution energy and hence the highest solubility is predicted for Sr. This is clearly illustrated in Fig. 2 which reveals a degree of correlation between the calculated solution energy and the size of the dopant ion, with a minimum at $\mathrm{Sr}^{2+}$ (close to the $\mathrm{La}^{3+}$ radius of $1.06 \AA$ ). The trends with dopant radius indicate the sensitivity of the interatomic potentials to small changes in ion size. Moreover, our results accord well with experimental studies which have demonstrated how the addition of $\mathrm{Sr}$ leads to the highest activity for a range of dopants. ${ }^{3,5,13}$

We are aware, however, that the solution energy is endothermic which suggests limited solubility in the host oxide at high temperatures unless additional stabilization occurs. It is

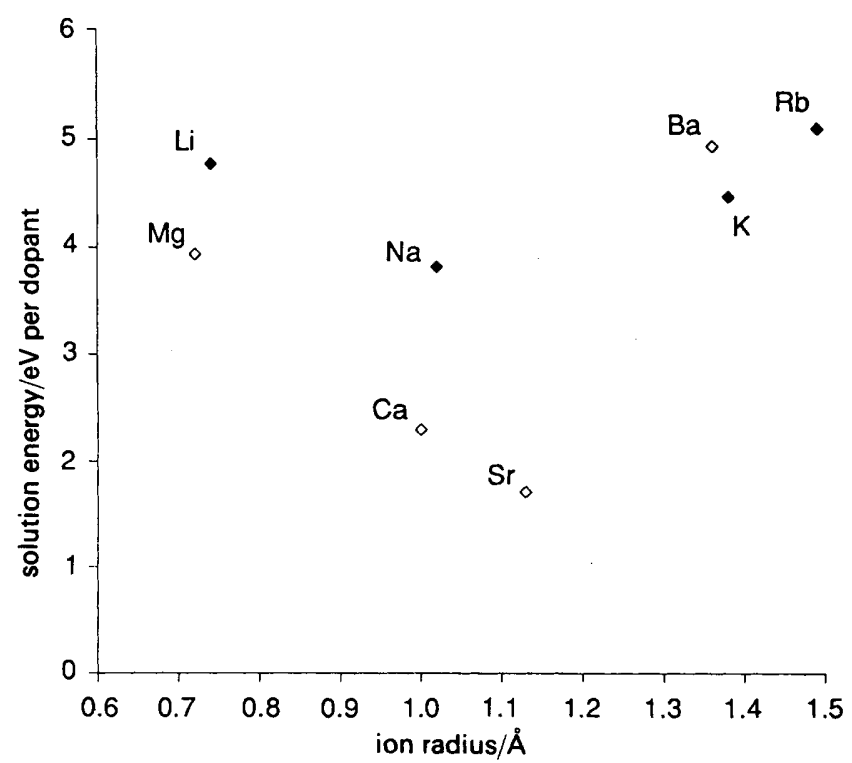

Fig. 2 Calculated energies of solution as a function of ion radius for alkali-metal and alkaline-earth-metal dopants. (Note that the $\mathrm{La}^{3+}$ radius is $1.06 \AA$.) well established that clustering can take place between dopant ions and their charge-compensating defects. From a preliminary investigation we have calculated a binding energy of $-0.78 \mathrm{eV}$ for the $\left(\mathrm{Sr}_{\mathbf{L a}}^{\prime} \mathrm{V}_{0}^{*}\right)$ pair cluster which will in effect reduce the solution energy by this stabilizing term; such calculations will form the basis of a subsequent publication. In any case, the present calculations demonstrate their qualitative importance in predicting the most favourable dopant substitution and thus provide a useful guide to dopant behaviour.

We note that an alternative compensation mechanism involving cation interstitials was also considered, but resulted in solution energies that were less favourable by at least $3 \mathrm{eV}$. This confirms the view that the majority defects created by incorporating these dopant ions will be oxygen vacancies (particularly at low oxygen pressures). Moreover, even for small additions of $\mathrm{SrO}$ the dopant-controlled vacancy concentration will far exceed that arising from thermal disorder and thereby enhance the oxygen mobility. We therefore conclude that the net flux of oxygen through the doped solid (and to the surface) will be high.

\section{Hole Centres in the Doped Oxide}

Various spectroscopic studies ${ }^{5,32}$ have demonstrated that the active sites in the $\mathrm{Li} / \mathrm{MgO}$ catalyst are $\mathrm{O}^{-}$hole species which are stabilized by the formation of $\left(\mathrm{Li}^{+} \mathrm{O}^{-}\right)$centres, and facilitate hydrogen-atom abstraction from methane. These studies also report that the majority of the $\mathrm{O}^{-}$centres are located in the bulk of the material. However, the issue of the active site for rare-earth-metal sesquioxides is not as clear, although the participation of $\mathrm{O}^{-}, \mathrm{O}_{2}^{-}$superoxide and $\mathrm{O}_{2}^{2-}$ peroxide species has been proposed. ${ }^{1,2,14}$ Calculations in this area can be useful in clarifying the nature of the redox reaction, together with the key energetic terms controlling the formation of oxygen holes in the doped oxide.

To render alkaline-earth-metal doped $\mathrm{La}_{2} \mathrm{O}_{3}$ catalytically active, it is necessary to treat the material with gaseous oxygen co-fed with methane. In terms of defect chemistry this leads to the oxidation (or 'filling') of oxygen vacancies by molecular oxygen with consequent formation of hole states. This oxidation reaction may be expressed as:

$$
\mathrm{V}_{0}^{*}+\frac{1}{2} \mathrm{O}_{2}(\mathrm{~g}) \rightarrow \mathrm{O}_{0}^{x}+2 \mathrm{~h}^{\cdot}
$$

where $\mathrm{O}_{0}^{x}$ is an oxygen anion on a normal site and $h^{*}$ is an electron hole modelled as a substitutional $\mathrm{O}^{-}$. As is mentioned earlier, a large polaron model for $\mathrm{O}^{-}$was found to be the most favourable. We note that this process is consistent with spectroscopic studies of Lunsford and co-workers ${ }^{2}$ who proposed that the active oxide species is derived from the reaction of molecular $\mathrm{O}_{2}$ with $\mathrm{La}_{2} \mathrm{O}_{3}$.

The calculated energy for the oxidation reaction $(\mathrm{X})$ is reported in Table 10 for the two independent oxygen sites. The first point to emerge from the results is that the $O(2)$ position is the most likely $\mathrm{O}^{-}$site. We therefore envisage the diffusion and filling of $O(1)$ vacancies will lead to the creation of holes on neighbouring $O(2)$ sites. Such an oxidation process involving hole formation at a site adjacent to the vacancy has also been proposed for the $\mathrm{Li} / \mathrm{MgO}$ catalyst. ${ }^{15}$

Table 10 Energies of oxidation reaction (oxygen vacancy to hole) in doped $\mathrm{La}_{2} \mathrm{O}_{3}$

\begin{tabular}{|c|c|}
\hline reaction & $E_{\mathrm{ox}} / \mathrm{eV}$ \\
\hline $\begin{array}{l}\mathrm{V}_{0}^{\ddot{1}}+\frac{1}{2} \mathrm{O}_{2}(\mathrm{~g}) \rightarrow \mathrm{O}_{0}^{x}+2 \mathrm{~h}^{*} \\
\quad \mathrm{O}(1) \text { site } \\
\mathrm{O}(2) \text { site }\end{array}$ & $\begin{array}{l}2.63 \\
0.80\end{array}$ \\
\hline
\end{tabular}


Table 11 Calculated binding energies of (dopant-hole) centres

\begin{tabular}{|c|c|}
\hline centre $^{a}$ & $E_{\mathrm{B}} / \mathrm{eV}^{b}$ \\
\hline 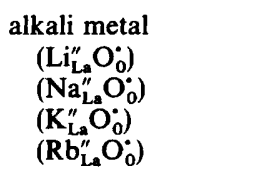 & $\begin{array}{l}-0.77 \\
-0.70 \\
-0.58 \\
-0.53\end{array}$ \\
\hline $\begin{array}{l}\text { alkaline-earth metal } \\
\left(\mathrm{Mg}_{\mathrm{La}}^{\prime} \mathrm{O}_{0}^{\prime}\right) \\
\left(\mathrm{Ca}_{\mathbf{L}}^{\prime} \mathrm{O}_{0}^{\circ}\right) \\
\left(\mathrm{Sr}_{\mathrm{La}}^{\prime} \mathrm{O}_{0}^{\circ}\right) \\
\left(\mathrm{Ba}_{\mathbf{L a}}^{\prime} \mathrm{O}_{0}^{\prime}\right)\end{array}$ & $\begin{array}{l}-0.56 \\
-0.44 \\
-0.30 \\
-0.20\end{array}$ \\
\hline
\end{tabular}

${ }^{a} \mathrm{O}^{-}$at $\mathrm{O}(2)$ position. ${ }^{b}$ Negative value indicates system is bound.

The present calculations predict a small endothermic energy at low temperatures although it is possible that other types of oxygen species could have higher stability. This energy, when compared with the uncertainties in the contributing free-ion terms, suggests a finely balanced equilibrium which could be displaced by changes in oxygen partial pressure. However, the entropic contribution of $\mathrm{O}_{2}(\mathrm{~g})$ to the total free energy will make this reaction less favourable at high temperatures. Nevertheless, our result is consistent with experimental findings ${ }^{9}$ which suggest that holes predominate at high oxygen partial pressures $(>0.1 \mathrm{kPa})$. Indeed, most, if not all, of the catalytic studies are carried out with oxygen partial pressures in excess of $5 \mathrm{kPa}$. Entropic effects need to be included in our calculations to derive a quantitative relationship between the oxygen partial pressure and the defect concentrations. This is obviously a topic for further study.

In addition to isolated states, calculations were performed on (dopant- $\mathrm{O}^{-}$) complexes comprised of nearest-neighbour species which have been linked to possible active sites. The results are reported in Table 11 which gives the binding energies with respect to the component isolated defects. Note that we have employed Kroger-Vink notation where, for example, $\left(\mathrm{Sr}^{2+} \mathrm{O}^{-}\right)$is written as $\left(\mathrm{Sr}_{\mathrm{La}}^{\prime} \mathrm{O}_{0}^{\circ}\right)$. The results reveal that in all cases the complexes are bound which is not too surprising in view of their opposite effective charges. In any event this suggests that the $\mathrm{O}^{-}$species are stabilised by the formation of (dopant- $\mathrm{O}^{-}$) entities. It should be added that such interactions do not necessarily preclude the presence of isolated species since clusters will be in equilibrium with single defects.

\section{Conclusions}

The present study has illustrated how computer simulation methods can contribute to the understanding of key solidstate properties of the $\mathrm{La}_{2} \mathrm{O}_{3}$ material that are relevant to its catalytic behaviour. Four main features emerge from the study:

(1) The anion Frenkel defect consisting of $\mathrm{O}^{2-}$ vacancies and interstitials, is calculated to be the predominant intrinsic disorder albeit at very low concentrations. Deviation from ideal stoichiometry is not significant in accord with the known properties of the material; the redox reactions confirm that cations with variable valence are not a prerequisite for oxidative coupling of methane. In practice, therefore, defect populations in $\mathrm{La}_{2} \mathrm{O}_{3}$ will be largely due to compensation for dopants or impurities.

(2) Oxygen diffusion will be associated with an interlayer vacancy mechanism [on the $O(1)$ sublattice] and hence anisotropic ion transport is anticipated for single crystal $\mathrm{La}_{2} \mathrm{O}_{3}$. Moreover, the low activation energy suggests that the oxygen vacancies consumed in the oxidation reaction will be readily replenished by fast diffusion through the bulk and to the catalyst surface.

(3) The majority compensating defects created by addition of alkaline-earth-metal (or alkali-metal) dopants will be $\mathrm{O}^{2-}$ vacancies and hence the net flux of oxygen through the doped solid will be high. The highest solubility is calculated for $\mathrm{Sr}$ and will thus be the most effective dopant in producing an appreciable vacancy concentration; this is consistent with experimental results which find the highest activity for $\mathrm{Sr}$ promoted $\mathrm{La}_{2} \mathrm{O}_{3}$.

(4) We suggest that the catalytic activity may be associated with the oxidation reaction:

$$
\mathrm{V}_{0}^{\ddot{*}}+\frac{1}{2} \mathrm{O}_{2}(\mathrm{~g}) \rightarrow \mathrm{O}_{0}^{x}+2 \mathrm{~h}^{*}
$$

in which $\mathrm{O}^{-}$holes (large polarons) are created from the 'filling' of oxygen vacancies by reactant molecular oxygen, for which we calculate a small endothermic energy for the low temperature limit. Oxygen hole centres are believed to facilitate hydrogen abstraction from methane but other species, such as $\mathrm{O}_{2}^{2-}$, need to be considered before firm predictions may be made. In either case, this oxidation reaction is consistent with the observed inactivity of the catalyst in the absence of gas-phase oxygen.

D.J.I. is supported by a SERC/CASE studentship with BP, Sunbury. We wish to thank M. Leslie, J. McNally, S. Ramdas, S. Parker and C. R. A. Catlow for helpful discussions. We also acknowledge the useful comments of the referees particularly in connection with the electronic defect calculations. The simulations were performed on the supercomputer facilities at the University of London Computer Centre.

\section{References}

1 K. Otsuka, K. Jinno and A. Morikawa, J. Catal., 1986, 100, 353.

2 C-H. Lin, K. D. Campbell, J-X. Wang and J. H. Lunsford, J. Phys. Chem., 1986, 90, 534; J-X. Wang and J. H. Lunsford, J. Phys. Chem., 1986, 90, 3891.

3 J. M. DeBoy and R. F. Hicks, J. Chem. Soc., Chem. Commun. 1988, 982.

4 K. D. Campbell, H. Zhang and J. H. Lunsford, J. Phys. Chem., $1988,92,750$.

5 G. J. Hutchings, J. R. Woodhouse and M. S. Scurrell, J. Chem. Soc., Faraday Trans. 1, 1989, 85, 2507.

6 A. Kooh, H. Mimoun and C. J. Cameron, Catalysis Today, $1989,4,333$.

7 S. J. Korf, J. A. Roos, J. M. Diphoorn, R. H. H. Veehof, J. G. van Ommen and J. R. H. Ross, Catalysis Today, 1989, 4, 279.

8 Y. Tong, M. P. Rosynek and J. H. Lunsford, J. Catalysis, 1990, 126, 291 .

9 A. G. Anshits, E. N. Voskresenskaya and L. I. Kurteeva, Catal. Lett., 1990, 6, 67.

10 J. L. Rehspringer, P. Poix, A. Kaddouri, D. Andriamasinoro and A. Kiennemann, Catal. Lett., 1991, 10, 111.

11 S. Becker and M. Baerns, J. Catal., 1991, 128, 512.

12 V. R. Choudhary and V. H. Rane, J. Catal., 1991, 130, 411; J. Catal., 1992, 135, 310.

13 Z. Kalenik and E. E. Wolf, Catal. Lett., 1991, 9, 441; Catalysis Today, 1992, 13, 255.

14 C. Louis, T. L. Chang, M. Kermarec, T. L. Van, J. M. Tatibouët and M. Che, Catalysis Today, 1992, 13, 283.

15 W. C. Mackrodt, Solid State Ionics, 1984, 12, 175; J. D. Foot, E. A. Colbourn and C. R. A. Catlow, J. Phys. Chem. Solids, 1988, 49, 1225; C. R. A. Catlow, R. A. Jackson and J. M. Thomas, J. Phys. Chem., 1990, 94, 7889.

16 J. M. Thomas and C. R. A. Catlow, Prog. Inorg. Chem., 1987, 35, 1; R. A. Jackson and C. R. A. Catlow, Mol. Simul., 1988, 1, 207; A. K. Nowak, C. J. J. Den Ouden, S. D. Pickett, B. Smit, A. K. Cheetham, M. F. M. Post and J. M. Thomas, J. Phys. Chem., $1991,95,848$.

17 M. S. Islam, M. Leslie, S. M. Tomlinson and C. R. A. Catlow, J Phys. C, 1988, 21, L109; M. S. Islam and R. C. Baetzold, Phys. Rev. B, 1989, 40, 10926; M. S. Islam and C. Ananthamohan, Phys. Rev. B, 1991, 44, 9492. 
18 M. Leslie, SERC Daresbury Laboratory Report, No. DL/SCI/ TM3IT, 1982 (unpublished).

19 Computer Simulation of Solids, Lecture Notes in Physics, ed. C. R. A. Catlow and W. C. Mackrodt, Springer, Berlin, 1982, vol. 166; C. R. A. Catlow, Ann. Rev. Mater. Sci., 1986, 16, 517.

20 B. G. Dick and A. W. Overhauser, Phys. Rev., 1958, 112, 90.

21 A. B. Lidiard, J. Chem. Soc., Faraday Trans. 2, 1989, 85, 341

22 H. R. Hoekstra, Inorg. Chem., 1966, 5, 754; A. F. Wells, Structural Inorganic Chemistry, Oxford University Press, Oxford, 1984.

23 X. Zhang, C. R. A. Catlow, S. C. Parker and A. Walls, J. Phys. Chem. Solids, 1992, 53, 761.

24 N. P. Bogoroditskii, V. V. Pasynkov, R. R. Basili and Y. M. Volokobinskii, Sov. Phys.-Dokl., (Engl. transl.), 1965, 10, 85.

25 P. Kofstad, Nonstoichiometry, Diffusion and Electrical Conductivity in Binary Metal Oxides, Wiley, New York, 1972.

26 N. L. Allan and W. C. Mackrodt, Philos. Mag. A, 1988, 58, 55; J. Am. Ceram. Soc., 1990, 73, 3175.
27 G. Thornton, Ph.D. Thesis, University of Oxford, 1976; R. G. Egdell, personal communication.

28 T. H. Etsell and S. N. Flengas, J. Electrochem. Soc., 1969, 116, 771.

29 S. J. Milne, R. J. Brook and Y. S. Zhen, Br. Ceram. Proc., 1989, 41, 243.

30 G. V. Lewis and C. R. A. Catlow, J. Phys., 1985, 18, 1149; G. V. Lewis, Ph.D. Thesis, University of London, 1983.

31 R. Burch, G. D. Squire and S. C. Tsang, Appl. Catal., 1988, 43, 105.

32 J-X. Wang and J. H. Lunsford, J. Phys. Chem., 1986, 90, 5883.

Paper 3/01276J; Received 4th March, 1993 